\title{
Activating oxidative phosphorylation by a pyruvate dehydrogenase kinase inhibitor overcomes sorafenib resistance of hepatocellular carcinoma
}

\author{
Y-C Shen ${ }^{1,2,3,4}$, D-L Ou ${ }^{5}, \mathrm{C} \mathrm{Hsu}{ }^{2,4,6}, \mathrm{~K}-\mathrm{L} \mathrm{Lin}{ }^{4}, \mathrm{C}-\mathrm{Y} \mathrm{Chang}^{4}, \mathrm{C}-\mathrm{Y} \mathrm{Lin}{ }^{7}, \mathrm{~S}-\mathrm{H} \mathrm{Liu}^{\star}{ }^{* 1}$ and A-L Cheng ${ }^{\star 2,5,6}$ \\ ${ }^{1}$ Graduate Institute of Toxicology, College of Medicine, National Taiwan University, Taipei, Taiwan; ${ }^{2}$ Department of Oncology, \\ National Taiwan University Hospital, Taipei, Taiwan; ${ }^{3}$ Department Medical Research, National Taiwan University Hospital, Taipei, \\ Taiwan; ${ }^{4}$ National Center of Excellence for Clinical Trial and Research, National Taiwan University Hospital, Taipei, Taiwan; \\ ${ }^{5}$ Graduate Institute of Oncology, College of Medicine, National Taiwan University, Taipei, Taiwan; ${ }^{6}$ Department and Internal \\ Medicine, National Taiwan University Hospital, Taipei, Taiwan and ${ }^{7}$ Graduate Institute of Environmental Health, School of Public \\ Health, National Taiwan University, Taipei, Taiwan
}

Background: Sorafenib is the only drug approved for the treatment of hepatocellular carcinoma (HCC). The bioenergetic propensity of cancer cells has been correlated to anticancer drug resistance, but such correlation is unclear in sorafenib resistance of HCC.

\begin{abstract}
Methods: Six sorafenib-naive HCC cell lines and one sorafenib-resistant HCC cell line (Huh-7R; derived from sorafenib-sensitive Huh-7) were used. The bioenergetic propensity was calculated by measurement of lactate in the presence or absence of oligomycin. Dichloroacetate (DCA), a pyruvate dehydrogenase kinase (PDK) inhibitor, and siRNA of hexokinase 2 (HK2) were used to target relevant pathways of cancer metabolism. Cell viability, mitochondrial membrane potential, and sub-G1 fraction were measured for in vitro efficacy. Reactive oxygen species (ROS), adenosine triphosphate (ATP) and glucose uptake were also measured. A subcutaneous xenograft mouse model was used for in vivo efficacy.
\end{abstract}

Results: The bioenergetic propensity for using glycolysis correlated with decreased sorafenib sensitivity $\left(R^{2}=0.9067\right.$, among sorafenib-naive cell lines; $P=0.003$, compared between Huh-7 and Huh-7 R). DCA reduced lactate production and increased ROS and ATP, indicating activation of oxidative phosphorylation (OXPHOS). DCA markedly sensitised sorafenib-resistant HCC cells to sorafenib-induced apoptosis (sub-G1 (combination vs sorafenib): Hep3B, $65.4 \pm 8.4 \%$ vs $13 \pm 2.9 \%$; Huh-7 R, $25.3 \pm 5.7 \%$ vs $4.3 \pm 1.5 \%$; each $P<0.0001)$, whereas siRNA of HK2 did not. Sorafenib $\left(10 \mathrm{mg} \mathrm{kg}^{-1}\right.$ per day) plus DCA (100 $\mathrm{mg} \mathrm{kg}^{-1}$ per day) also resulted in superior tumour regression than sorafenib alone in mice (tumour size: $-87 \%$ vs $-36 \%, P<0.001$ ).

Conclusion: The bioenergetic propensity is a potentially useful predictive biomarker of sorafenib sensitivity, and activation of OXPHOS by PDK inhibitors may overcome sorafenib resistance of HCC.

Advanced hepatocellular carcinoma (HCC) is characterised by inherent resistance to all systemic treatments. Sorafenib, a multikinase inhibitor targeting tumour angiogenesis and
Raf/MEK/ERK pathway, is the only drug approved for patients with advanced HCC (Bruix and Sherman 2011). However, sorafenib is beneficial in only around $30 \%$ of patients, and 
acquired resistance often develops within 6 months (Llovet et al, 2008; Cheng et al, 2009). No effective therapies are available after sorafenib failure.

Cancer cells usually rely more on glycolysis than glucose oxidative phosphorylation (OXPHOS) in energy production. This reprogrammed cancer metabolism, characterised by enhanced glycolysis and suppressed OXPHOS, is known as the Warburg effect (Hsu and Sabatini, 2008; Kroemer and Pouyssegur 2008; Vander Heiden et al, 2009; Cairns et al, 2011; Koppenol et al, 2011). The Warburg effect is considered a metabolic adaptation in response to cellular alterations caused by oncogenes, tumour suppressor genes, mitochondria and microenvironment, and has increasingly been recognised as a hallmark of cancer (Hanahan and Weinberg, 2011; Ward and Thompson, 2012). Moreover, the Warburg effect is closely associated with either inherent or acquired drug resistance in cancer cells (Fanciulli et al, 2000; Hulleman et al, 2009; Kominsky et al, 2009; Zhao et al, 2010; Kluza et al, 2011; Zhou et al, 2011). Agents that target glycolysis such as inhibitors of hexokinase 2 (HK2) and lactate dehydrogenase-A have shown promising efficacy in the conversion of drug resistance in several in vitro models (Fanciulli et al, 2000; Hulleman et al, 2009; Zhao et al, 2010; Fiume et al, 2011; Kluza et al, 2011; Zhao et al, 2011; Zhou et al, 2011).

HCC is frequently associated with increased expression of glucose transporters (Amann and Hellerbrand 2009a; Amann et al, 2009b) and glycolytic enzymes (Taketa et al, 1988; Hugo-Wissemann et al, 1991), decreased expression of $\mathrm{H}^{+}$-adenosine triphosphate (ATP) synthases, and mutations of mitochondrial DNA-encoding components of electron-transfer chain complexes (Cuezva et al, 1997; Lee et al, 2009). These metabolic features are consistent with the Warburg effect. The correlation between the Warburg effect and sorafenib resistance of HCC cells is unclear. We hypothesised that the resistance of HCC cells to sorafenib is mediated by the Warburg effect and may be overcome by targeting cancer metabolism. In this study, we confirmed the close association between the bioenergetic propensity and degrees of sorafenib sensitivity in a panel of HCC cell lines. We also found evidence that activation of OXPHOS by pyruvate dehydrogenase kinase (PDK) inhibitior dichloroacetate (DCA) can sensitise HCC cells to sorafenib through ERKindependent mechanism. Our results indicate that the bioenergetic propensity is not only a useful biomarker of sorafenib sensitivity but also a potential target for therapeutic intervention.

\section{MATERIALS AND METHODS}

Cell lines and culture. A panel of sorafenib-naive human HCC cell lines was used in the in vitro experiments: Hep3B, HepG2, PLC/PRF/5 (PLC-5) (purchased from American Type Culture Collection, Manassas, VA, USA); Huh-7 (purchased from the Health Science Research Resources Bank, Osaka, Japan); and HCC36 and HA22T (obtained from Professor Hey-Chi Hsu, Graduate Institute of Pathology, College of Medicine, National Taiwan University, Taipei, Taiwan). A sorafenib-resistant HCC cell line (Huh-7R) was generated in our laboratory by continuously exposing Huh-7 cells to sorafenib (maximum concentration, $10 \mu \mathrm{M}$ ) as previously reported (Ou et al, 2010). HCC cells were cultured in regular Dulbecco's modified Eagle's medium (DMEM; Biological Industries, Kibbutz Beit Haemek, Israel) supplemented with $10 \%$ fetal bovine serum (unless indicated otherwise), penicillin $\left(100 \mathrm{U} \mathrm{ml}^{-1}\right), \quad$ streptomycin $\left(100 \mu \mathrm{g} \mathrm{ml}^{-1}\right)$ and L-glutamine $\left(2 \mathrm{mmoll}^{-1}\right)$, and were maintained at $37^{\circ} \mathrm{C}$ in a humidified incubator containing $5 \% \mathrm{CO}_{2}$ and $21 \% \mathrm{O}_{2}$.

Sorafenib and interventions targeting cancer metabolism. Sorafenib (Nexavar) was kindly provided by Bayer Pharmaceuticals Corporation (Montville, NJ, USA). Sorafenib was dissolved in dimethyl sulfoxide (Sigma-Aldrich, St. Louis, MO, USA) to reach a final concentration below $0.1 \%$ for in vitro experiments or in Cremophor EL/95\% ethanol (50:50, Sigma-Aldrich) for in vivo experiments.

Dichloroacetate, a PDK inhibitor that has been used for over a decade to treat congenital lactic acidosis (Stacpoole et al, 1998, 2003, 2006; Li et al, 2008; Stacpoole et al, 2008) was used to target cancer metabolism. The mechanism of action of DCA is shown in Supplementary Figure S1. Briefly, DCA inhibits PDK-mediated inactivation of pyruvate dehydrogenase $(\mathrm{PDH})$ and preferentially diverts glucose metabolism from glycolysis towards OXPHOS. DCA (Sigma-Aldrich) was dissolved in sterile deionised water for both in vitro and in vivo experiments.

HK2 silencing by using Silencer Select siRNAs from Ambion was also carried out to inhibit glycolysis without affecting OXPHOS. Hep3B and Huh-7R cells were seeded in six-well plates and transfected with negative control (NC) siRNA (20 nм) (Ambion, Austin, TX, USA) or siRNA of HK2 (20 nM) (Ambion) with lipofectamine 2000 (Invitrogen, Carlsbad, CA, USA). Twentyfour hours after transfection, medium was replaced with antibioticfree medium to prevent cytotoxicity from the transfection reagent. Cells or medium were collected at $48 \mathrm{~h}$ for measurement of lactate, glucose, reactive oxygen species (ROS) and ATP, and at $96 \mathrm{~h}$ for western blotting and sub-G1 analysis.

Measurement of bioenergetic propensity. The bioenergetic propensity of HCC cells were determined as previously reported (Hao et al, 2010). Briefly, HCC cells $\left(1-3 \times 10^{4}\right.$ cells per well) were seeded in 24-well plates overnight, and then washed and incubated in serum-free DMEM supplemented with or without $100 \mathrm{ng} \mathrm{ml}^{-1}$ oligomycin (an inhibitor of ATP synthase to maximally suppress OXPHOS; Sigma-Aldrich) for $6 \mathrm{~h}$. Culture medium $(50 \mu \mathrm{l})$ was collected from each sample and measured for lactate concentration using a lactate ELISA kit (Biovision, Mountain View, CA, USA). In response to oligomycin-induced OXPHOS suppression, cells increase their glucose uptake and glycolysis activity, to maintain the intracellular level of ATP. Lac (c) denotes the lactate concentration in the medium after $6 \mathrm{~h}$ of incubation in the absence of oligomycin, and Lac (o) denotes the lactate concentration in the medium after $6 \mathrm{~h}$ of incubation in the presence of oligomycin. The components of glycolysis and OXPHOS in the bioenergetic constitution were calculated with the following formula: Glycolysis (\%) = Lac (c)/Lac (o) $\times 100 ; \operatorname{OXPHOS~}(\%)$ $=100-$ glycolysis (\%).

Measurement of lactate production. Decreased lactate production was used as a surrogate marker of glycolysis inhibition. Briefly, HCC cells were treated with DCA $(0-60 \mathrm{~mm})$ in serum-free medium for $12 \mathrm{~h}$. Levels of lactate in the culture medium after DCA treatment were measured with a lactate ELISA kit (Biovision, Mountain View, CA, USA) according to the manufacturer's instructions, and normalised to the control group.

Measurement of cell viability. Cell viability after various treatments for $72 \mathrm{~h}$ was assessed by the MTT assay (Sigma-Aldrich) as previously described (Ou et al, 2009), and was normalised to the control group. The $\mathrm{IC}_{50}$ values of sorafenib and those of DCA were calculated using CompoSyn software (CompoSyn) (Chou and Hayball, 1997), based on the changes in absorbance measured by spectrophotometry (DTX 880; Beckman Coulter, Fullerton, CA, USA). Differences in potential synergistic growth inhibition between sorafenib and DCA were assessed by Chou-Talalay median effect analysis. The combination indices (CIs) after drug treatment were calculated using CompoSyn software (ComboSyn). The CI values of $<1,1$, and $>1$ indicated synergistic, additive, and antagonistic effects, respectively.

Measurement of apoptosis. The following three methods were used to assess treatment-induced apoptosis. First, reduction in 
mitochondrial membrane potential $(\Delta \Psi \mathrm{m})$, indicating the opening of the mitochondrial transition pole and initiation of intrinsic apoptosis, was measured using tetramethylrhodamine ethyl ester (TMRE; Molecular Probes, Eugene, OR, USA). In brief, HCC cells $\left(7 \times 10^{4}-5 \times 10^{5}\right.$ cells per well) were seeded and cultured in sixwell plates overnight, and then treated with sorafenib, DCA or both for $24 \mathrm{~h}$. After washing with PBS, HCC cells were stained with $200 \mathrm{~nm}$ TMRE for $20 \mathrm{~min}$ and then analysed by flow cytometry analysis software (FlowJo v.7.6.5; Tree Star Inc., Ashland, OR, USA). The median fluorescent intensity (MFI) of each treatment group was normalised to the control group. Second, the percentage of cells in the sub-G1 phase after drug treatment for $72 \mathrm{~h}$ was assessed by flow cytometry (Ou et al, 2009). Third, the expression of apoptosis-related proteins, such as cytochrome $c$, caspases 3,7 and 9, was evaluated using western blot that were described later.

Measurement of intracellular level of reactive oxygen species. Intracellular levels of ROS after 24-h exposure of drug treatments were measured by using CM-H2DCFDA (Invitrogen, Eugene, OR, USA). Briefly, HCC cells after 24-h exposure of study drugs or 48-h transfection of siRNA of HK2 or NC were washed with PBS and then loaded with CM-H2DCFDA $(10 \mu \mathrm{M})$ for $30 \mathrm{~min}$ at $37^{\circ} \mathrm{C}$. Fluorescent intensities were measured by using flow cytometer and analysed by flow cytometry analysis software (FlowJo v.7.6.5). MFI of each treatment group was normalised to the control group. Exposure of $\mathrm{H}_{2} \mathrm{O}_{2}(0.5 \mathrm{mM})$ for $30 \mathrm{~min}$ was used as positive internal control.

Measurement of intracellular level of ATP. Intracellular levels of ATP were measured by using CellTiter-Glo(r) luminescent assay (Promega, Madison, WI, USA), and normalised to the control group.

Measurement of glucose uptake. HCC cells were incubated in regular DMEM containing $25 \mathrm{~mm}$ glucose overnight or transfected with siRNA of $\mathrm{NC}$ or HK2 for $24 \mathrm{~h}$. After removal of the culture medium, the cells were treated with various drugs which were prepared in low glucose ( $5 \mathrm{~mm}$ ) DMEM containing $10 \%$ fetal bovine serum for $24 \mathrm{~h}$. Similar levels of cell viability at $24 \mathrm{~h}$ between regular and low glucose DMEM have been confirmed. Cell viability of the same treatment was simultaneously measured by MTT assay. The glucose concentration in the medium of each sample was measured by using glucose assay kit (Biovision, Milpitas, CA, USA). Glucose uptake of each sample was calculated with the following formula: Glucose uptake (nmole per well) $=($ glucose in blank medium - glucose in the medium of the treatment group)/ OD value of viability, and then normalised to the control group.

Western blotting. Western blot analysis was used to examine the expression levels of glucose transporter 1, key glycolytic enzymes, apoptosis-related proteins, and ERK signalling in HCC cells. Whole-cell lysates of HCC cells were prepared and quantified as previously described (Ou et al, 2009). The cytosolic fraction of HCC cells after drug treatment was extracted with a cell fractionation kit (MitoScience, Eugene, OR, USA) for measurement of cytochrome $c$ expression. Antibodies against glucose transporter 1, HK2, enolase 1 (Abcam, Cambridge, MA, USA), pyruvate kinase-M2, glyceraldehyde 3-phosphate dehydrogenase, pyruvate dehydrogenase E1 $\alpha$ subunit, caspases 9, 7 and 3 (Cell Signaling, Danvas, MA, USA), lactate dehydrogenase-A, ERK2 (D-2), phosphorylated ERK (E-4), cytochrome $c$, $\alpha$-tubulin (Santa Cruz, Santa Cruz, CA, USA), and $\beta$-actin (Sigma-Aldrich) were used. Signals were visualised with X-ray film.

In vivo experiments. The protocol of the in vivo studies was approved by the Institutional Animal Care and Use Committee of the College of Medicine, National Taiwan University. Male 6- to 8 -week-old BALB/c athymic $(\mathrm{nu}+/ \mathrm{nu}+)$ mice (purchased from the National Laboratory of Animal Breeding and Research Center,
Taipei, Taiwan; http://www.nlac.org.tw/) were subcutaneously inoculated with Hep3B cells $\left(1 \times 10^{6}\right.$ cells $)$ in serum-free medium containing 50\% Matrigel (BD Biosciences, Bedford, MA, USA). Mice were randomised into four groups ( $n=5$ per group) $7-10$ days after inoculation: (1) vehicle (control); (2) DCA $100 \mathrm{mg}$ per kg body weight (bw) per day; (3) sorafenib $10 \mathrm{mg}$ per $\mathrm{kg}$ bw per day; and (4) DCA $100 \mathrm{mg}$ per kg bw per day combined with sorafenib $10 \mathrm{mg}$ per $\mathrm{kg}$ bw per day. All treatments were administered via gavages for 1 (for measurement of apoptosis) or 3 weeks. The selected daily dose of DCA was similar to the dose consumed by mice that drink DCA-containing water $\left(0.5 \mathrm{gl}^{-1}\right)$ on a daily basis. Studies have shown that daily consumption of DCA-containing water $\left(0.5 \mathrm{gl}^{-1}\right)$ resulted in increased PDH activity in mouse tissue (Andreassen et al, 2001) and a serum level of DCA equivalent to that in humans who consume DCA (Stacpoole et al, 1998; Schultz et al, 2002; Stacpoole et al, 2003, 2006; Li et al, 2008; Stacpoole et al, 2008). Tumour volume was calculated using the following formula: volume $\left(\mathrm{mm}^{3}\right)=(\text { width })^{2} \times$ length $\times 0.5$. Tumour volume and body weight were measured twice weekly. The terminal deoxynucleotidyl transferase-mediated dUTP nick end labelling (TUNEL) assay was used to measure the extent of tumour cell apoptosis (Ou et al, 2009). The number of TUNEL-positive tumour cells was determined by counting the average number of cells under four high-power fields $(\times 200)$ in each sample.

Statistical analyses. Quantitative data are expressed as mean \pm s.d. of at least three independent experiments. Qualitative data are representative of at least three independent experiments. Linear regression was used to assess the correlation between degree of glycolysis and $\mathrm{IC}_{50}$ of sorafenib. Comparisons were analysed using the Student's $t$ test or ANOVA test. Statistical significance was defined as $P<0.05$.

\section{RESULTS}

The bioenergetic propensity for using glycolysis is highly associated with resistance of HCC cells to sorafenib. The sorafenib-naive HCC cell lines tested had various $\mathrm{IC}_{50}$ values of sorafenib (range: 1.6-23.5 $\mu \mathrm{M}$ ) and propensities for using glycolysis (range: 66.5-91.7\%) (Figure 1A). Enhanced glycolysis or suppressed OXPHOS correlated well with increased $\mathrm{IC}_{50}$ of sorafenib $\left(R^{2}=0.9067\right)$.

Acquired sorafenib-resistant Huh-7R cells, compared with their sorafenib-sensitive parent Huh-7 cells, had a higher $\Delta \Psi \mathrm{m}$ (MFI of $\Delta \Psi \mathrm{m}: 2.12 \pm 0.14$ vs $1 \pm 0, P<0.001$ ) (Figure $1 \mathrm{~B}$ ), indicating prominent resistance to initiate mitochondrial apoptosis. The $\mathrm{IC}_{50}$ value of sorafenib was $12.7 \pm 1.4 \mu \mathrm{M}$ in Huh-7R cells and $6.1 \pm 1.5 \mu \mathrm{M}$ in Huh-7 cells. Ten micromolar sorafenib failed to either reduce $\Delta \Psi \mathrm{m}$ or elicit apoptosis in Huh-7R cells as it did in Huh-7 cells $(\Delta \Psi \mathrm{m}$ relative to untreated control: $+10.8 \%$ for Huh$7 \mathrm{R} v s-83.4 \%$ for Huh-7; fold increase of apoptotic cells relative to untreated control: 1.37 for Huh-7R vs 33.3 for Huh-7) (Figure 1B). Upon emergence of acquired sorafenib resistance, Huh-7R cells, compared with Huh-7 cells, relied more on glycolysis for bioenergesis $(93.4 \pm 2.3 \%$ for Huh-7R vs $71.0 \pm 5.6 \%$ for Huh-7, $P=0.003$ ) (Figure 1C). The higher expression of HK2 and lower expression of the PDH E1 $\alpha$ subunit in Huh-7R cells were consistent with the highly glycolysing phenotype of Huh-7R cells. Taken together, enhanced glycolysis or suppressed OXPHOS is closely associated with resistance of HCC cells to sorafenib.

DCA synergistically enhances sorafenib-induced growth suppression in highly glycolysing HCC cells. DCA increased PDH activity (data not shown), reduced lactate production, and suppressed cell growth in a dose-dependent manner in all HCC cell lines tested (Figure 2A). Higher concentrations (30 and $60 \mathrm{~mm}$ ) of DCA were required to remarkably suppress either lactate 

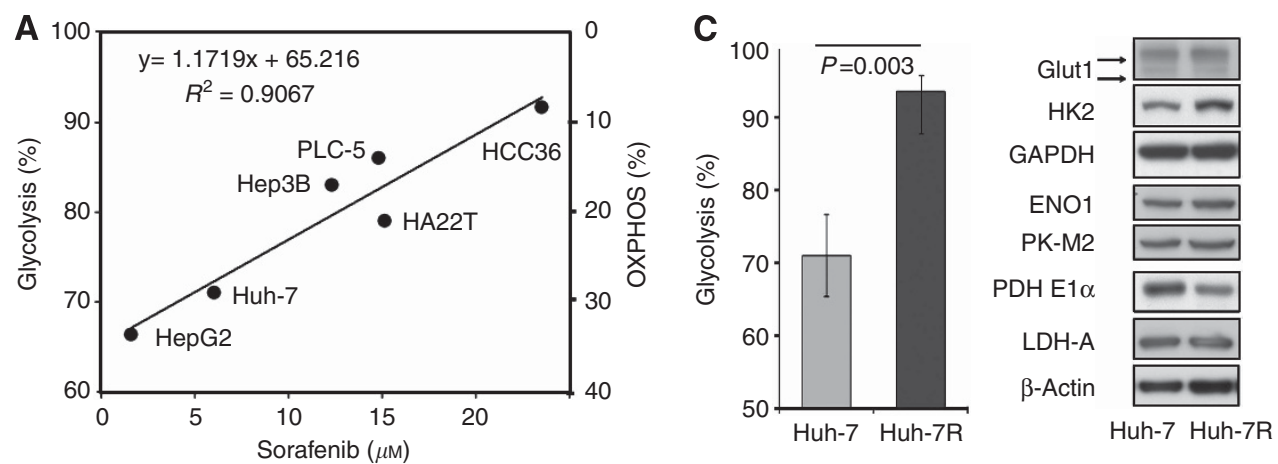

\begin{tabular}{|c|c|c|c|c|c|c|}
\hline & HepG2 & Huh-7 & HA22T & Hep3B & PLC-5 & HCC36 \\
\hline $\begin{array}{c}\text { Glycolysis } \\
(\%)\end{array}$ & $66.5 \pm 4.9$ & $71 \pm 5.6$ & $79 \pm 7.0$ & $83 \pm 5.7$ & $86 \pm 12$ & $91.7 \pm 6.7$ \\
\hline $\begin{array}{c}\mathrm{IC}_{50} \text { of sorafenib } \\
(\mu \mathrm{M})\end{array}$ & 1.6 & 6.0 & 15.1 & 12.3 & 14.8 & 23.5 \\
\hline
\end{tabular}
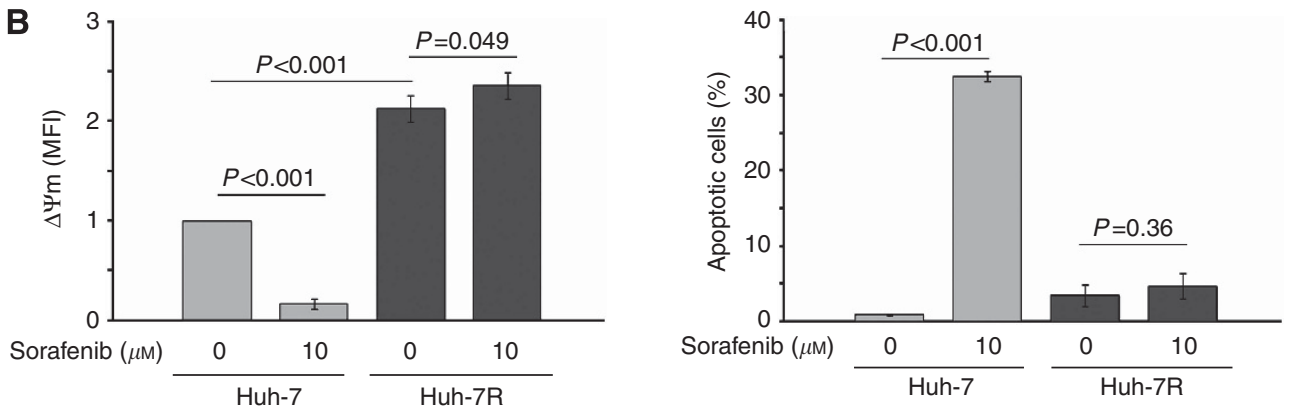

Figure 1. Enhanced glycolysis or suppressed OXPHOS is correlated well with sorafenib resistance of HCC cells. (A) Correlation between bioenergetic propensity and $I C_{50}$ values of sorafenib in a panel of sorafenib-naive HCC cells is shown. (B) Left panel: Huh-7 and Huh-7R cells were seeded with the same cell number. Changes in $\Delta \Psi \mathrm{m}$ of Huh-7 and Huh-7R cells after 24-h exposure of sorafenib (0 and $10 \mu \mathrm{m})$ were measured simultaneously. Right panel: percentages of apoptotic cells (cells in sub-G1 phase) after 72-h exposure of sorafenib (0 and $10 \mu \mathrm{m})$ are shown. (C) Comparisons between Huh-7 and Huh-7R cells in bioenergetic propensity (left panel) and protein expressions of glucose transporter 1 (Glut1), hexokinase 2 (HK2), glyceraldehyde 3-phosphate dehydrogenase (GAPDH), enolase 1 (ENO1), pyruvate kinase-M2 (PK-M2), pyruvate dehydrogenase (PDH) E1 $\alpha$, and lactate dehydrogenase-A (LDH-A) (right panel) are shown. Protein expression of $\beta$-actin was used as loading control. In B and C (left panel), columns represent mean values; whereas bars represent s.d.

production or cell growth. The $\mathrm{IC}_{50}$ values of DCA ranged from 22.0 to $65.5 \mathrm{~mm}$ (data not shown).

Furthermore, DCA synergistically enhanced sorafenib-induced growth suppression, shown as CI $<1$ for all combinations of DCA and sorafenib, in all HCC cell lines except HepG2 and Huh-7 cells (the two most oxidative and sorafenib-sensitive HCC cell lines) (Figure 2B and Supplementary table 1). The results suggest that targeting cancer metabolism by DCA might improve sensitivity to sorafenib in highly glycolysing HCC cells.

DCA sensitises sorafenib-resistant HCC cells to sorafenibinduced apoptosis. Two highly glycolysing cell lines, Hep3B and Huh-7R, were used as representative HCC cells with inherent and acquired sorafenib resistance, respectively. Thirty milimolar DCA was used to target cancer metabolism.

In Hep3B cells, sorafenib ( $5 \mu \mathrm{M})$ alone, DCA alone, and the twodrug combination significantly reduced $\Delta \Psi \mathrm{m}$ by $63.6 \pm 6.7 \%$, $17.3 \pm 9.7 \%$, and $71.8 \pm 7.0 \%$, respectively, in comparison with untreated control ( $P$-value: $<0.0001,0.0120$, and $<0.0001$, respectively) (Figure $3 \mathrm{~A}$ and Supplementary figure $\mathrm{S} 2$ ). The magnitude of $\Delta \Psi \mathrm{m}$ reduction was consistent with the amount of cytochrome $c$ released from mitochondrion into cytosol (Figure $3 \mathrm{C}$ ). It suggests $\Delta \Psi \mathrm{m}$ reduction as a reliable indicator of initiation of mitochondrial apoptosis in HCC cells. While combining with sorafenib, DCA later on sensitised Hep3B cells to sorafenib-induced apoptosis (sub-G1 fraction: $65.4 \pm 8.4 \%$ for combination $v s 13.0 \pm 2.9 \%$ for sorafenib alone, $P<0.001)$ through enhanced activation of caspases 9, 7, and 3 (Figures $3 \mathrm{~B}$ and $\mathrm{C}$ ).

In Huh-7R cells, neither sorafenib $(10 \mu \mathrm{M})$ nor DCA initiated or propagate apoptosis (Figures $3 \mathrm{D}$ and $\mathrm{E}$ and Supplementary figure S2). However, DCA while combining with $10 \mu \mathrm{M}$ sorafenib significantly initiated mitochondrial apoptosis (relative $\Delta \Psi \mathrm{m}$ : $78.4 \pm 4.5 \%$ for combination $v s 112.4 \pm 9.1 \%$ for sorafenib alone, $P=0.0061$ ), as well as propagated apoptosis (sub-G1 fraction: $25.3 \pm 5.7 \%$ for combination vs $4.3 \pm 1.5 \%$ for sorafenib, $P<0.0001)$.

The reversal of sorafenib resistance by DCA is closely linked with activation of OXPHOS rather than suppression of glycolysis. DCA significantly increased ROS production by $19.5 \pm 6.0 \%$ in Hep3B cells and by $15.1 \pm 6.1 \%$ in Huh-7R cells (each $P<0.0001$, compared with untreated control), as well as ATP production by $42.3 \pm 7.2 \%$ in Hep3B cells and by $18.7 \pm 6.0 \%$ in Huh-7R cells (each $P<0.0001$, compared with untreated control) (Figure 4 and Supplementary Figure S3) after 24-h exposure. DCA also reduced glucose uptake by $6.9 \pm 0.9 \%$ in Hep3B and $38.7 \pm 3.1 \%$ in Huh-7R cells $(P=0.0088$ and 0.0032 , respectively, compared with untreated control) at the same time. Therefore, DCA facilitated ATP production primarily by activating OXPHOS, rather than increasing glucose uptake and metabolism. Addition 
A

Sorafenib naive

Sorafenib resistant
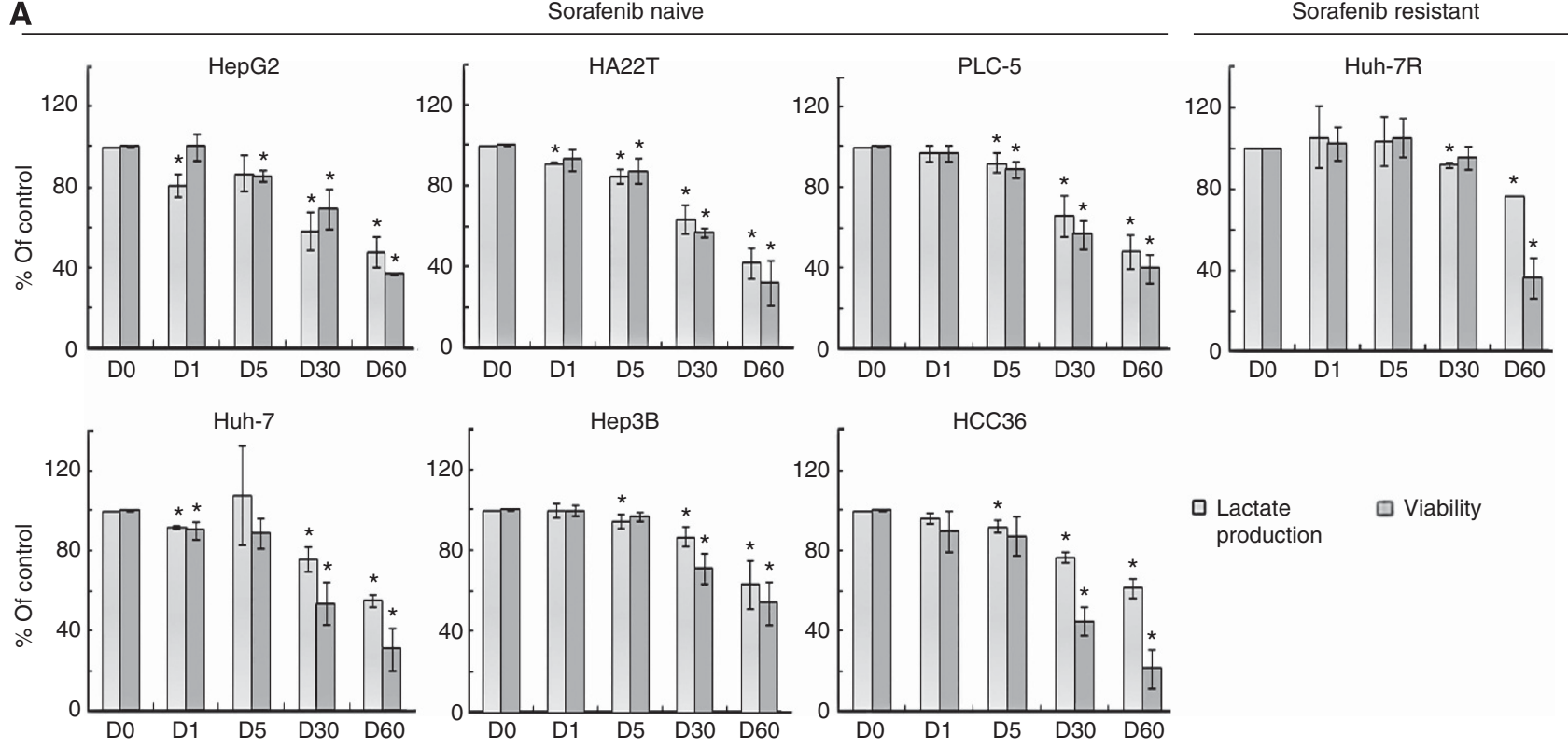

B
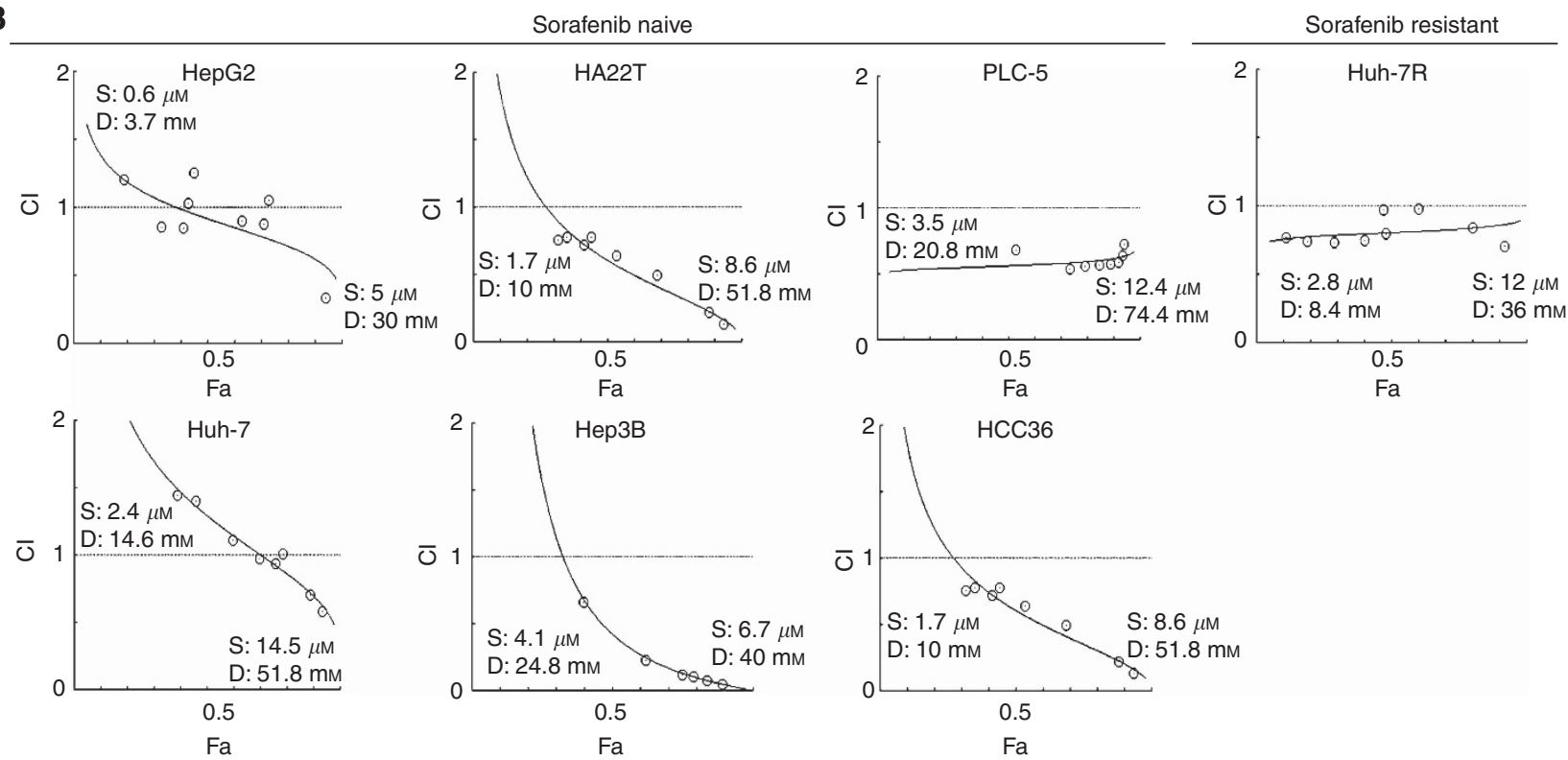

Figure 2. PDK inhibitor DCA synergistically enhanced growth suppression of sorafenib in highly glycolysing, sorafenib-resistant HCC cells. (A) Sorafenib-naive and sorafenib-resistant HCC cells were exposed to various concentrations of DCA (0-60 mM) for $12 \mathrm{~h}$ for measurement of lactate production and for $72 \mathrm{~h}$ for measurement of cell viability. Columns represent mean values of lactate levels and viability relative to untreated control cells; whereas bars represent s.d. *Denotes $P<0.05$, compared with untreated controls. (B) Combination indexes (Cls) of DCA and sorafenib in sorafenib-naive and sorafenib-resistant HCC cells were measured by median effect analysis. The representative figure of each cell line is shown. The concentration ranges of sorafenib (S) and DCA (D) tested in each cell line are shown. Fa denotes fraction of death. Detailed information was shown in Supplementary Table 1.

of DCA significantly increased ROS production in Hep3B $(124.2 \pm 14.0 \%$ for combination vs $87.4 \pm 11.0 \%$ for sorafenib alone, $P=0.0058)$ and Huh-7R $(175.0 \pm 10.9 \%$ for combination $v s$ $75.2 \pm 11.8 \%$ for sorafenib alone, $P=0.0003)$ cells.

HK2 silencing by siRNA was more potent than DCA $(30 \mathrm{~mm})$ in suppressing lactate production in both Hep3B $(39.6 \pm 3.9 \%$ for siRNA of HK2 vs $15.3 \pm 1.7 \%$ for DCA) and Huh-7R $(25.2 \pm 10.5 \%$ for siRNA of HK2 vs $7.9 \pm 1.1 \%$ for DCA) cells (Figures $5 \mathrm{~B}$ and 2A). HK2 silencing significantly decreased glucose uptake and had a trend to decrease ATP and ROS production (Supplementary figure S4). siRNA of HK2 modestly reduced $\Delta \Psi \mathrm{m}$ and failed to propagate apoptosis in both cells (Figure 5C). While combining with sorafenib, siRNA of HK2 mildly enhanced sorafenib-induced apoptosis in Huh-7R cells (relative $\Delta \Psi \mathrm{m}$ : $101.7 \pm 1.6 \%$ for combination vs $109.2 \pm 3.0 \%$ for sorafenib alone, $P=0.0183$; subG1 fraction: $10.4 \pm 1.1 \%$ for combination $v s \quad 6.3 \pm 0.7 \%$ for sorafenib alone, $P=0.0123$ ), but not in Hep3B cells. Taken together, the results suggest that activation of OXPHOS is more important than suppression of glycolysis in overcoming sorafenib resistance of highly glycolysing HCC cells.

The reversal of sorafenib resistance by DCA is not attributed to enhanced inhibition of ERK signalling. Sorafenib $(5 \mu \mathrm{M})$ inhibited phosphorylation of ERK until $24 \mathrm{~h}$ in Hep3B, whereas 
A

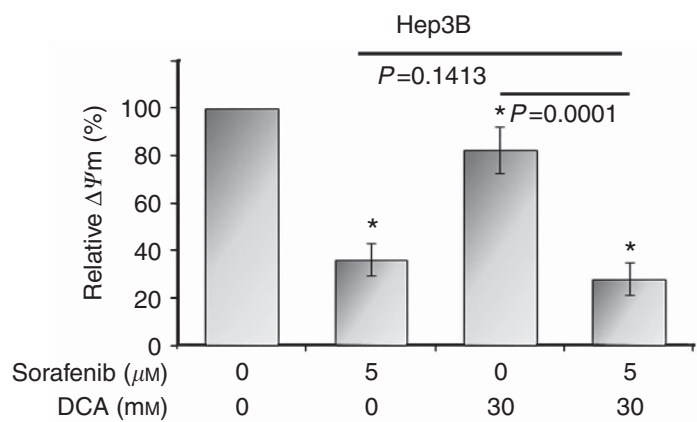

B

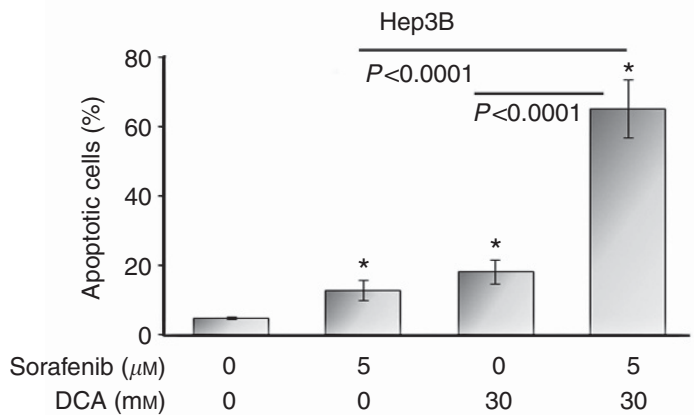

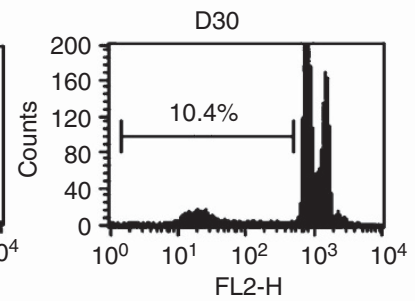
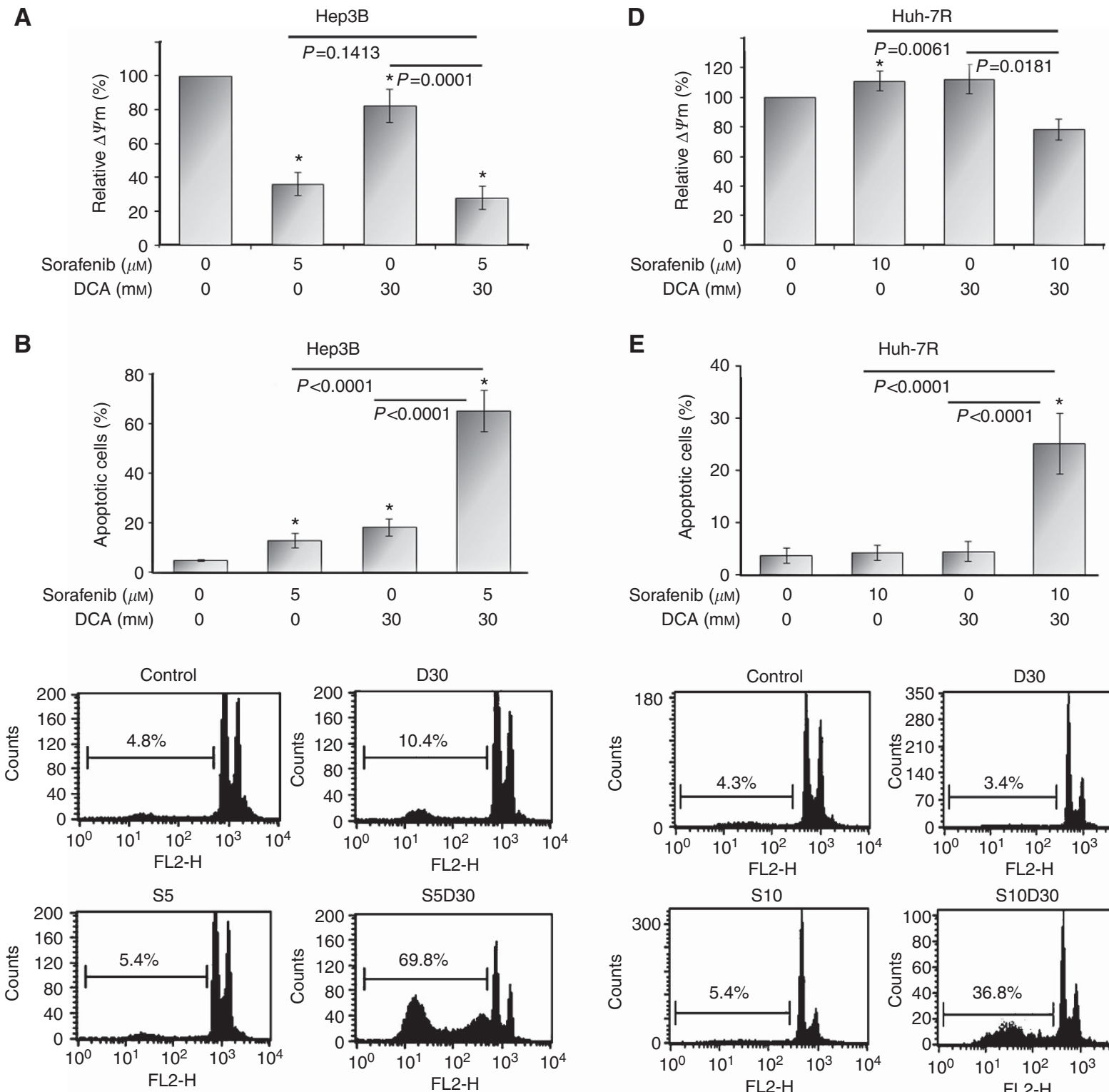

E
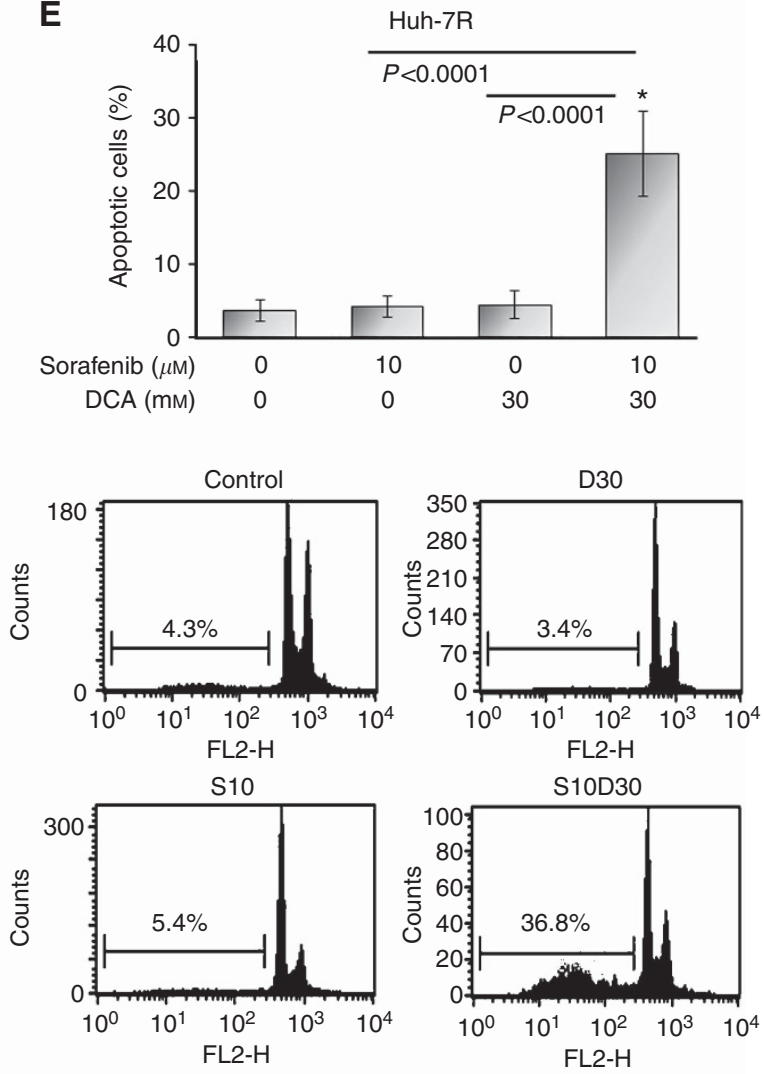

C

Sorafenib $(\mu \mathrm{M}) \quad 0 \quad 5 \quad 0 \quad 5$

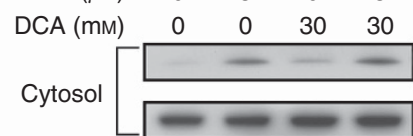

Cytochrome $c$

Beta-actin

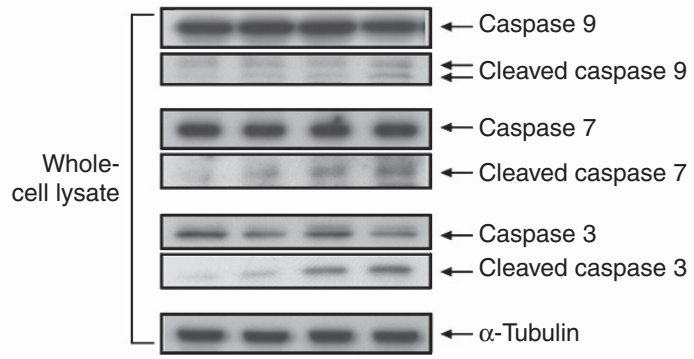

Figure 3. DCA sensitised both inherent and acquired sorafenib-resistant HCC cells (Hep3B and Huh-7R, respectively) to sorafenib-induced apoptosis. Hep3B cells were exposed to sorafenib $(5 \mu \mathrm{M})$ alone, DCA $(30 \mathrm{~mm})$ alone, and combined treatment for $24 \mathrm{~h}$ for measurement of $\Delta \Psi \mathrm{m}(\mathbf{A})$ and for $72 \mathrm{~h}$ for measurement of apoptosis by sub-G1 analysis (B). Western blotting was carried out for cytochrome $c$ and $\beta$-actin (loading control) using cytosol fraction extracted from Hep3B cells after aforementioned treatments for $24 \mathrm{~h}$ and for caspases 9,7 and 3 and $\alpha$-tubulin (loading control) using whole-cell lysates extracted after treatments for $48 \mathrm{~h}$ (C). Huh-7R cells were exposed to sorafenib (10 $\mu \mathrm{m}$ ) alone, DCA ( $30 \mathrm{~mm}$ ) alone, and combined treatment for $24 \mathrm{~h}$ for measurement of $\Delta \Psi \mathrm{m}(\mathrm{D})$ and for $72 \mathrm{~h}$ for measurement of apoptosis by sub-G1 analysis (E). The representative figures of sub-G1 analyses are shown in the lower panels of (B) and (E). Columns represent mean values; while bars represent s.d. ${ }^{*}$ Denotes $P<0.05$ compared with untreated control. 

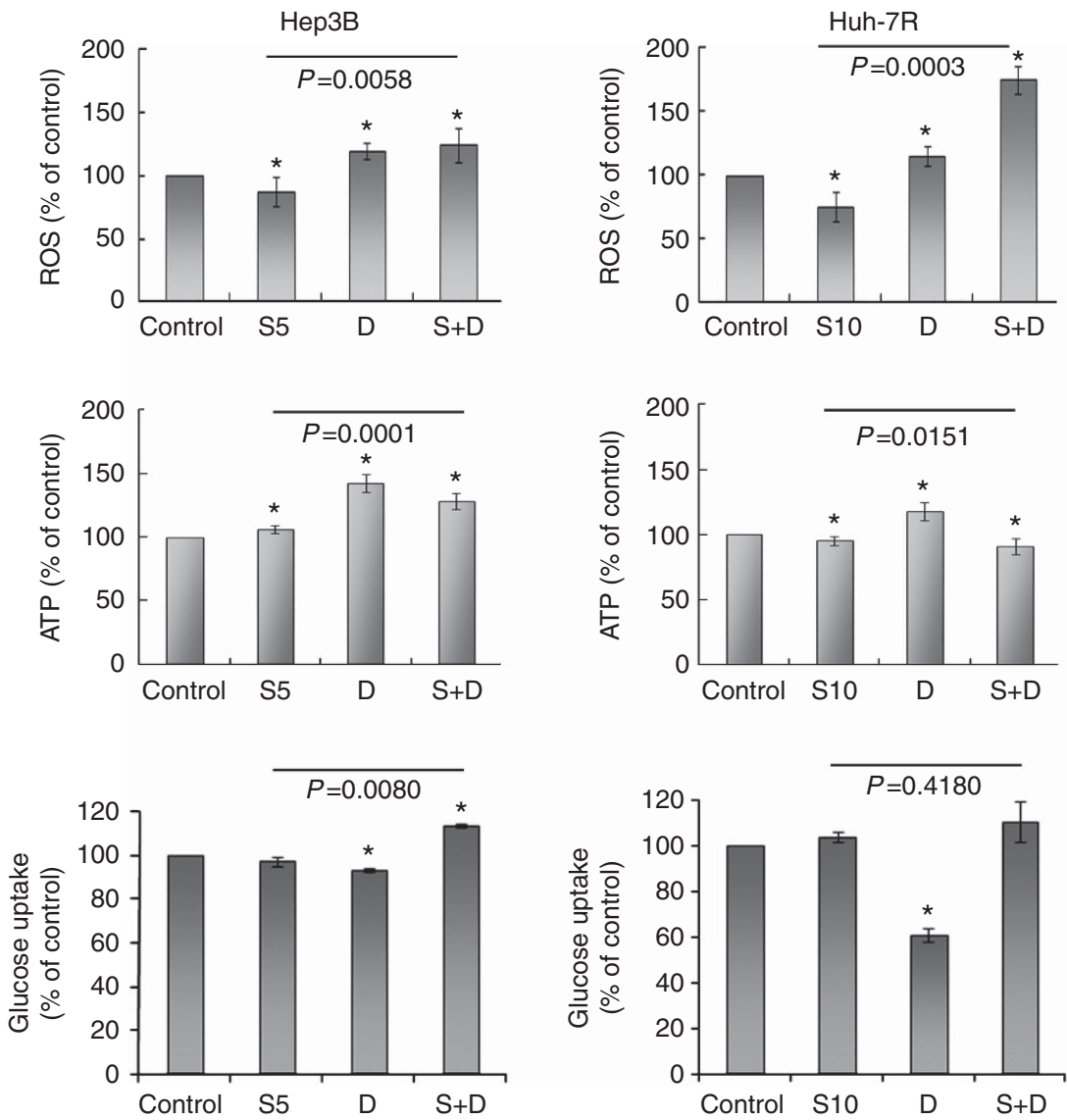

Figure 4. Metabolic effects of treatment after 24-h exposure on intracellular levels of ROS (upper panel) and ATP (middle panel) and glucose uptake (lower panel) are shown. Columns represent mean values; while bars represent s.d. *Denotes $P<0.05$ compared with untreated control. S5, $5 \mu \mathrm{m}$ sorafenib; S10, $10 \mu \mathrm{m}$ sorafenib; D, $30 \mathrm{~mm}$ DCA; S + , sorafenib combined with DCA.

sorafenib $(10 \mu \mathrm{M})$ failed to inactivate ERK until $24 \mathrm{~h}$ in Huh-7R (Supplementary figure S5). In addition, DCA did not enhance sorafenib-induced ERK inactivation in either Hep3B or Huh-7R cells. It indicates that DCA sensitised anticancer activities of sorafenib against HCC through an ERK signalling-independent mechanism.

DCA improved the in vivo efficacy of sorafenib. Combination of DCA (100 mg per kg bw per day) and sorafenib (10 mg per $\mathrm{kg}$ bw per day), compared with sorafenib alone, significantly suppressed tumour growth (relative tumour size to vehicle-treated tumours after 3-week treatment: $-87 \%$ vs $-36 \%, P<0.001$; Figure 6A) and apoptosis (TUNEL-positive tumour cells on day 8: $2.4 \%$ vs $1.2 \%, P=0.039$; Figure $6 \mathrm{~B}$ and Supplementary figure S6). No apparent body weight loss or toxicities were observed throughout the 3-week treatment course (Figure 6C). Our results provide in vivo evidence that targeting cancer metabolism by DCA sensitises HCC cells to sorafenib-induced apoptosis.

\section{DISCUSSIONS}

In this study, we demonstrated that the bioenergetic propensity for using glycolysis is closely associated with sorafenib resistance, and that activation of OXPHOS, rather than suppression of glycolysis, can overcome both inherent and acquired sorafenib resistance of HCC cells. We have provided solid rationales for further clinical trials testing either examination of the bioenergetic propensity of HCC to predict the efficacy of sorafenib or activation of OXPHOS by PDK inhibitors as a measure of enhancing therapeutics efficacy of sorafenib.

Sorafenib is the only drug that has been shown to prolong survival of patients with HCC in randomised controlled trials; however, its modest efficacy and high rate of intolerance limit the utility of sorafenib in the general population of HCC patients (Welker et al, 2010; Morimotoo et al, 2011). To date, there are no reliable predictive biomarkers for sorafenib sensitivity that can be used to guide the personalised use of sorafenib. In this study, we have demonstrated that the bioenergetic propensity for using glycolysis is a potential biomarker of sorafenib sensitivity. ${ }^{18} \mathrm{~F}$-fluorodeoxyglucose-positron emission tomography and ${ }^{1} \mathrm{H}$ magnetic resonance spectroscopy (MRS) are currently available non-invasive modalities for evaluating the bioenergetic phenotype of tumours in HCC patients. ${ }^{18} \mathrm{~F}$-FDG PET scan has been standard care that applies the Warburg effect in detection and diagnosis of cancer. ${ }^{18} \mathrm{~F}$-FDG uptake is positively correlated with expression of glucose transporter 1 and HK2 in HCC; therefore, ${ }^{18}$ F-FDG uptake is a good activity indicator of glucose uptake and glycolysis (Torizuka et al, 1995; Ong et al, 2008; Paudyal et al, 2008). A recent prospective study has showed that higher baseline FDG uptake is associated with shorter survival of HCC patients receiving sorafenib (Lee et al, 2011). In vivo ${ }^{1} \mathrm{H}$ - MRS has been rapidly evolved for diagnosis and therapeutic monitoring in cancer research (Kim et al, 2011; Voqlein et al, 2011). In vivo ${ }^{1} \mathrm{H}-\mathrm{MRS}$ allows non-invasive quantitative measurement of not only metabolites of interest, such as lactate, but also the global metabolic profile in the tumour (Dagnelie and Leij-Halfwerk, 2010; ter Voert et al, 2011). Therefore, ${ }^{1} \mathrm{H}$ - MRS represents an ideal 
A

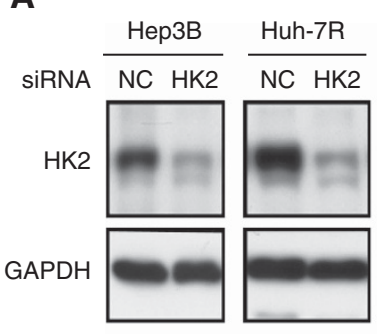

B

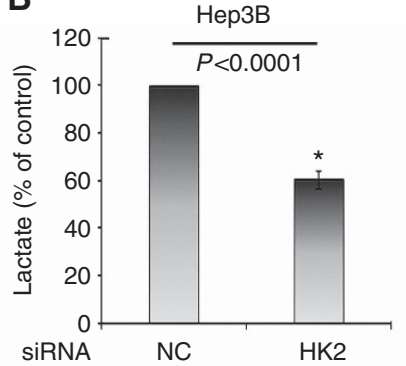

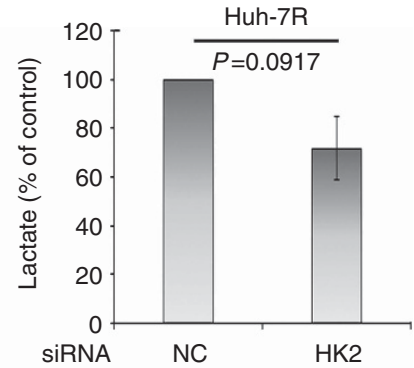

C
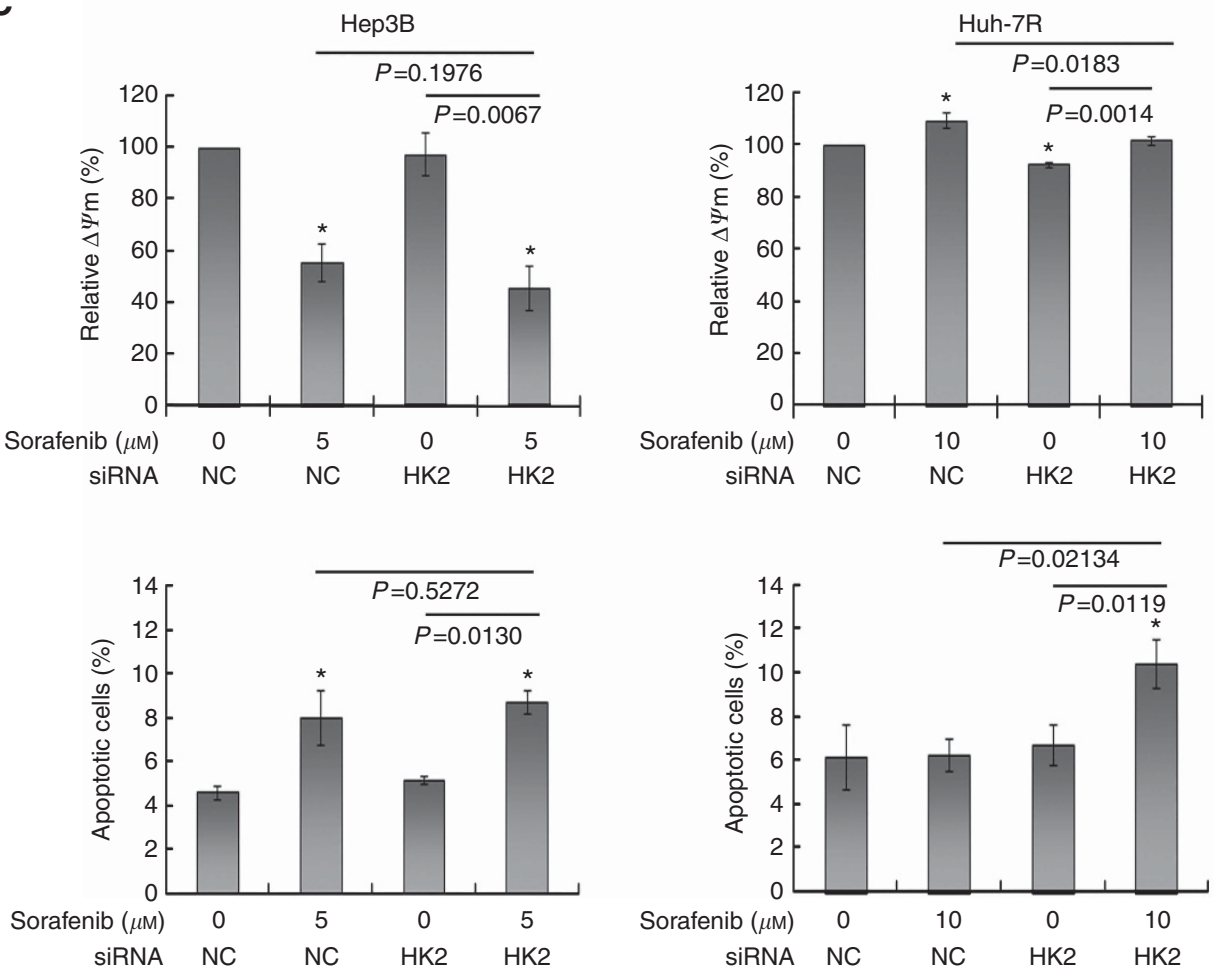

Figure 5. Inhibition of glycolysis by using siRNA of HK2 did not sensitise sorafenib-resistant HCC cells to sorafenib-induced apoptosis. Protein expression of HK2 after transfection with siRNA of HK2 in Hep3B and Huh-7R cells was decreased in a time-dependent manner (48-96 h). Data at $96 \mathrm{~h}$ are shown in A. Transfection with siRNA of HK2 for $48 \mathrm{~h}$ significantly reduced lactate production in Hep3B and Huh-7R cells (B). Transfection with siRNA of HK2 did not remarkably enhance sorafenib-induced apoptosis measured by either mitochondrial membrane potential or sub-G1 analysis in both Hep3B and Huh-7R cells (C). NC denotes negative control. Columns represent mean values; whereas bars represent s.d. *Denotes $P<0.05$ compared with untreated control.

imaging modality to simultaneously monitor the bioenergetic propensity and objective tumour response during sorafenib therapy.

Differential expressions of PDH E1 $\alpha$ and HK2 between sorafenib-sensitive and sorafenib-resistant HCC cells (Figure 1C) provide a rationale to target cancer metabolism by using PDK inhibitors (namely PDH activators) or HK2 inhibitors. However, our results demonstrated that activation of OXPHOS, instead of inhibition of glycolysis, is more relevant to reversing sorafenib resistance of HCC cells, and is therefore warranted to be tested in clinical trials. DCA is the most appropriate and available agent to activate OXPHOS in future trials because of its well-established and favourable pharmacokinetic and safety profiles in patients with congenital mitochondrial defect (Stacpoole et al, 1998, 2003, 2006; Li et al, 2008; Stacpoole et al, 2008). Targeting cancer metabolism by DCA alone or in combination with radiotherapy has shown promising efficacy in patients with refractory glioblastoma multiform (Michelakis et al, 2010).

Cumulative amount of evidence has shown that the Warburg effect contributes to resistance of cancer cells to various types of anticancer drugs (Fanciulli et al, 2000; Hulleman et al, 2009; Kominsky et al, 2009; Zhao et al, 2010; Kluza et al, 2011; Zhou et al, 2011), however, the underlying mechanisms remain largely unknown. The Warburg effect provides cancer cells with survival advantages in energy production, biosynthesis, redox control and evasion from intrinsic apoptosis, which may offset the efficacy of anticancer drugs (Hsu and Sabatini, 2008; Kroemer and Pouyssegur, 2008; Vander Heiden et al, 2009; Koppenol et al, 2011; Cairns et al, 2011). In the current study, DCA appears to reverse sorafenib resistance primarily through activation of OXPHOS. Competent electron-transfer chain complexes have been recognised as sensors of apoptosis (Lemarie and Grimm, 2011); therefore, activation of OXPHOS by DCA may release sorafenib-resistant HCC cells from an anti-apoptotic status. In addition, increased ROS production following activation of OXPHOS has been considered a key event underlying apoptosis induction by DCA (Bonnet et al, 2007; Michelakis et al, 2008; Sun et al, 2011). However, our preliminary data showed that ROS scavenger $\mathrm{N}$-acetyl cysteine did not reverse apoptosis induced by DCA and sorafenib (data not shown). Further studies are required 

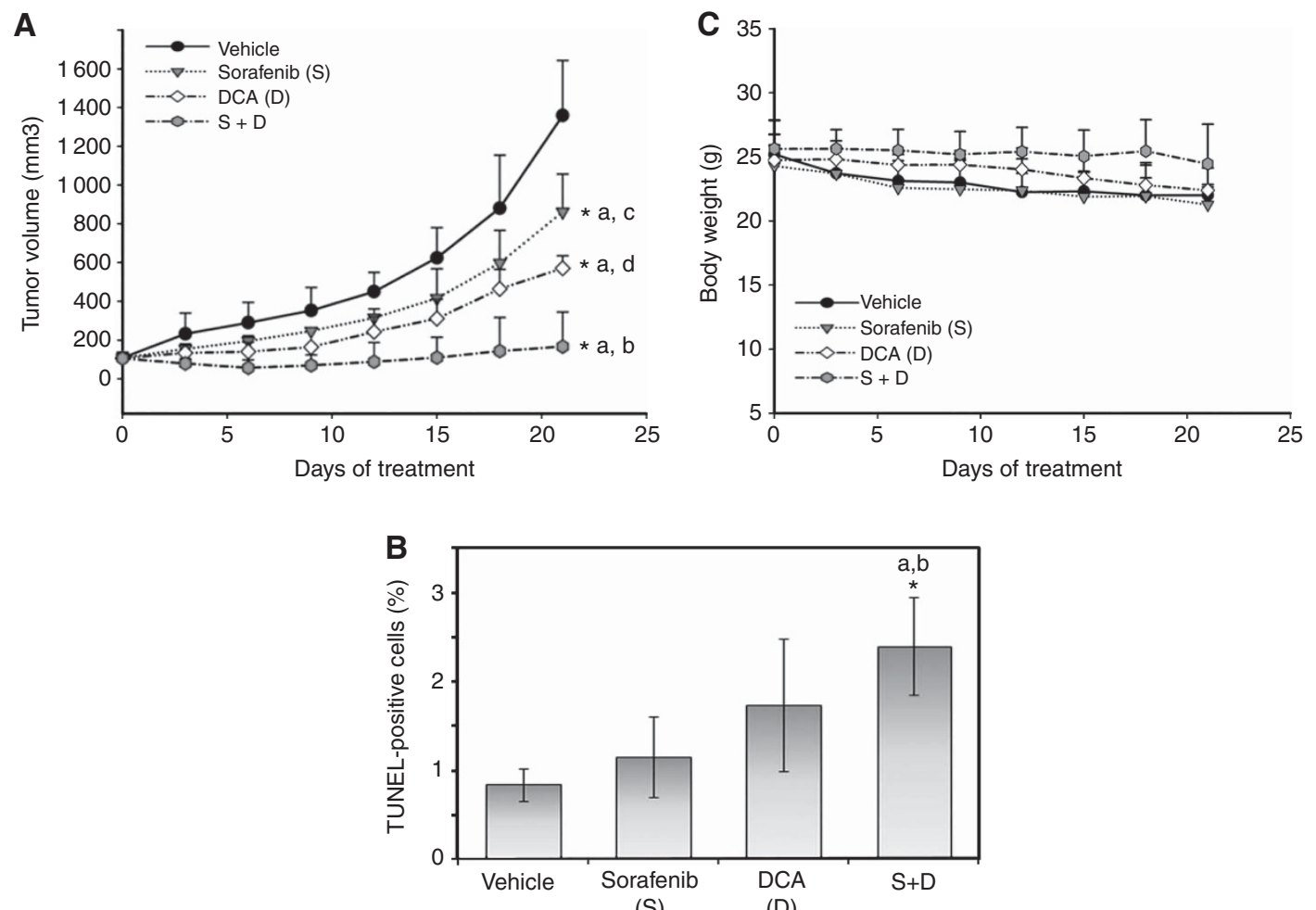

(S)

(D)

Figure 6. DCA significantly potentiated tumour suppression and apoptosis induction of sorafenib in a subcutaneous xenograft mouse model. Tumour volumes (A), the proportion of TUNEL-positive tumour cells (B), and changes in body weight (bw) (C) among mice treated with vehicle, sorafenib (10 mg per kg bw per day), DCA (100 mg per kg bw per day) or combined treatment are shown. Points or columns represent mean values, whereas bars represent s.d. *Denotes $P<0.05$, compared with vehicle control (a), sorafenib or DCA alone (b), DCA alone (c) and sorafenib alone (d).

to elucidate what role ROS has in the reversal of sorafenib resistance by DCA.

In conclusion, the bioenergetic propensity appears to contribute to both inherent and acquired resistance of HCC cells to sorafenib. It represents a new direction to develop predictive biomarkers for sorafenib resistance, as well as a new target to develop drugs for reversing sorafenib resistance of HCC.

\section{ACKNOWLEDGEMENTS}

We thank Sheng-Chieh Liao and Hsiang-Hsuan Fan at the National Center of Excellence for Clinical Trial and Research, National Taiwan University Hospital, for their technical support. This study was supported by grants NSC98-3112-B-002-007, NSC98-3112-B-002-037, and NSC100-2314-B-002-063 from the National Science Council, Taiwan, and the grant NTUH.99-M1449 from the National Taiwan University Hospital.

\section{CONFLICT OF INTEREST}

The authors declare no conflict of interest.

\section{REFERENCES}

Amann T, Hellerbrand C (2009a) GLUT1 as a therapeutic target in hepatocellualr carcinoma. Expert Opin Ther Targets 13: 1411-1427.

Amann T, Maegdefrau U, Hartmann A, Agaimy A, Marienhagen J, Weiss TS, Stoeltzing O, Warnecke C, Schölmerich J, Oefner PJ, Kreutz M,

Bosserhoff AK, Hellerbrand C (2009b) GLUT1 expression is increased in hepatocellular carcinoma and promotes tumorigenesis. Am J Pathol 174: 1544-1552.

Andreassen OA, Ferrante RJ, Huang HM, Dedeoglu A, Park L, Ferrante KL, Kwon J, Borchelt DR, Ross CA, Gibson GE, Beal MF (2001)

Dichloroacetate exerts therapeutic effects in transgenic mouse models of Huntington's disease. Ann Neurol 50: 112-117.

Bonnet S, Archer SL, Allalunis-Turner J, Haromy A, Beaulieu C, Thompson R, Lee CT, Lopaschuk GD, Puttagunta L, Bonnet S, Harry G, Hashimoto K, Porter CJ, Andrade MA, Thebaud B, Michelakis ED (2007) A mitochondrial- $\mathrm{K}+$ channel axis is suppressed in cancer and its normalization promotes apoptosis and inhibits cancer growth Cancer Cell 11: 37-51.

Bruix J, Sherman M (2011) Management of hepatocellular carcinoma: an update. Hepatology 53: 1020-1022.

Cairns RA, Harris IS, Mak TW (2011) Regulation of cancer cell metabolism. Nat Rev Cancer 11: 85-95.

Cheng AL, Guan Z, Chen Z, Tsao CJ, Qin S, Kim JS, Luo R, Feng J, Ye S, Yang TS, Xu J, Sun Y, Liang H, Liu J, Wang J, Tak WY, Pan H, Burock K, Zou J, Voliotis D, Guan Z (2009) Efficacy and safety of sorafenib in patients in the Asia-Pacific region with advanced hepatocellular carcinoma: a phase III randomised, double-blind, placebo-controlled trial. Lancet Oncol 10: 25-34.

Chou TC, Hayball MP (1997) CalcuSyn for Windows: Multiple-Drug Dose Effect Analyzer and Manual. Biosoft: Cambridge (UK).

Cuezva JM, Ostronoff LK, Ricart J, López de Heredia M, Di Liegro CM, Izquierdo JM (1997) Mitochondrial biogenesis in the liver during development and oncogenesis. J Bioenerg Biomembr 29: 365-377.

Dagnelie PC, Leij-Halfwerk S (2010) Magnetic resonance spectroscopy to study hepatic metabolism in diffuse liver disease, diabetics and cancer. World J Gastroenterol 16: 1577-1586.

Fanciulli M, Bruno T, Giovannelli A, Gentile FP, Di Padova M, Rubiu O, Floridi A (2000) Energy metabolism of human LoVo colon carcinoma cells: correlation to drug resistance and influence of lonidamine. Clin Cancer Res 6: 1590-1597. 
Fiume L, Vettraino M, Manerba M, Di Stefano G (2011) Inhibition of lactic dehydrogenase as a way to increase the anti-proliferative effect of multitargeted kinase inhibitors. Pharmacol Res 63: 328-334.

Hanahan D, Weinberg RA (2011) Hallmarks of cancer: the next generation. Cell 144: 646-674.

Hao W, Chang CP, Tsao CC, Xu J (2010) Oligomycin-induced bioenergetic adaptation in cancer cells with heterogeneous bioenergetic organization. J Biol Chem 285: 12647-12654.

Hsu PP, Sabatini DM (2008) Cancer cell metabolism: Warburg and beyond. Cell 134: 703-707.

Hugo-Wissemann D, Anundi I, Lauchart W, Viebahn R, de Groot H (1991) Differences in glycolytic capacity and hypoxia tolerance between hepatoma cells and hepatocytes. Hepatology 13: 297-303.

Hulleman E, Kazemier KM, Holleman A, VanderWeele DJ, Rudin CM, Broekhuis MJ, Evans WE, Pieters R, Den Boer ML (2009) Inhibition of glycolysis modulates prednisolone resistance in acute lymphoblastic leukemia cells. Blood 113: 2014-2021.

Kim H, Catana C, Ratai EM, Andronesi OC, Jennings DL, Batchelor TT, Jain RK, Sorensen AG (2011) Serial magnetic resonance spectroscopy reveals a direct metabolic effect of cediranib in glioblastoma. Cancer Res 71: 3745-3752.

Kluza J, Jendoubi M, Ballot C, Dammak A, Jonneaux A, Idziorek T, Joha S, Dauphin V, Malet-Martino M, Balayssac S, Maboudou P, Briand G, Formstecher P, Quesnel B, Marchetti P (2011) Exploiting mitochondrial dysfunction for effective elimination of imatinib-resistant leukemic cells. PLoS ONE 6: e21924.

Kominsky DJ, Klawitter J, Brown JL, Boros LG, Melo JV, Eckhardt SG, Serkova NJ (2009) Abnormalities in glucose uptake and metabolism in imatinib-resistant human BCR-ABL-positive cells. Clin Cancer Res 15: 3442-3450.

Koppenol WH, Bounds PL, Dang CV (2011) Otto Warburg's contributions to current concepts of cancer metabolism. Nat Rev Cancer 11: 325-337.

Kroemer G, Pouyssegur J (2008) Tumor cell metabolism: cancer's Achilles' heel. Cancer Cell 13: 472-482.

Lee JH, Park JY, Kim do Y, Ahn SH, Han KH, Seo HJ, Lee JD, Choi HJ (2011) Prognostic value of 18F-FDG PET for hepatocellular carcinoma patients treated with sorafenib. Liver Int 31: 1144-1149.

Lemarie A, Grimm S (2011) Mitochondrial respiratory chain complexes: apoptosis sensors mutated in cancer. Oncogene 30: 3985-4003.

Li T, Schultz I, Keys DA, Campbell JL, Fisher JW (2008) Quantitative evaluation of dichloroacetic acid kinetics in human-a physiologically based pharmacokinetic modeling investigation. Toxicology 245: 35-48.

Llovet JM, Ricci S, Mazzaferro V, Hilgard P, Gane E, Blanc JF, de Oliveira AC, Santoro A, Raoul JL, Forner A, Schwartz M, Porta C, Zeuzem S, Bolondi L, Greten TF, Galle PR, Seitz JF, Borbath I, Häussinger D, Giannaris T, Shan M, Moscovici M, Voliotis D, Bruix J. SHARP Investigators Study Group (2008) Sorafenib in advanced hepatocellular carcinoma. N Engl J Med 359: 378-390.

Michelakis ED, Sutendra G, Dromparis P, Webster L, Haromy A, Niven E, Maguire C, Gammer TL, Mackey JR, Fulton D, Abdulkarim B, McMurtry MS, Petruk KC (2010) Metabolic modulation of glioblastoma with dichloroacetate. Sci Transl Med 2: 31ra34.

Michelakis ED, Webster L, Mackey JR (2008) Dichloroacetate (DCA) as a potential metabolic-targeting therapy for cancer. $\mathrm{Br} J$ Cancer 99 : 989-994.

Morimotoo M, Numata K, Kondo M, Hidaka H, Takada J, Shibuya A, Kobayashi S, Ohkawa S, Okuse C, Morita S, Taguri M, Tanaka K (2011) Higher discontinuation and lower survival rates are likely in elderly Japanese patients with advanced hepatocellular carcinoma receiving sorafenib. Hepatol Res 41: 296-302.

Ong LC, Jin Y, Song IC, Yu S, Zhang K, Chow PK (2008) 2-[18F]-2-deoxy-Dglucose (FDG) uptake in human tumor cells is related to the expression of GLUT-1 and hexokinase II. Acta Radiol 9: 1145-1153.

Ou DL, Shen YC, Liang JD, Liou JY, Yu SL, Fan HH, Wang DS, Lu YS, Hsu C, Cheng AL (2009) Induction of Bim expression contributes to the antitumor synergy between sorafenib and mitogen-activated protein kinase/extracellular signal-regulated kinase kinase inhibitor CI-1040 in hepatocellular carcinoma. Clin Cancer Res 15: 5820-5828.
Ou DL, Shen YC, Yu SL, Chen KF, Yeh PY, Fan HH, Feng WC, Wang CT, Lin LI, Hsu C, Cheng AL (2010) Induction of DNA damage-inducible gene GADD $45 \beta$ contributes to sorafenib-induced apoptosis in hepatocellular carcinoma cells. Cancer Res 70: 9309-9318.

Paudyal B, Paudyal P, Oriuchi N, Tsushima Y, Nakajima T, Endo K (2008) Clinical implication of glucose transport and metabolism evaluated by 18F-FDG PET in hepatocellular carcinoma. Int J Oncol 33: 1047-1054.

Schultz IR, Merdink JL, Gonzalez-Leon A, Bull RJ (2002) Dichloroacetate toxicokinetics and disruption of tyrosine catabolism in B6C3F1 mice: dose-response relationships and age as a modifying factor. Toxicology 173: 229-247.

Stacpoole PW, Henderson GN, Yan Z, Cornett R, James MO (1998) Pharmacokinetics, metabolism, and toxicology of dichloroacetate. Drug Meta Rev 30: 499-539.

Stacpoole PW, Kerr DS, Barnes C, Bunch ST, Carney PR, Fennell EM, Felitsyn NM, Gilmore RL, Greer M, Henderson GN, Hutson AD, Neiberger RE, O'Brien RG, Perkins LA, Quisling RG, Shroads AL, Shuster JJ, Silverstein JH, Theriaque DW, Valenstein E (2006) Controlled clinical trial of dichloroacetate for treatment of congenital lactic acidosis in children. Pediatrics 17: 1519-1531.

Stacpoole PW, Kurtz TL, Han Z, Langaee T (2008) Role of dichloroacetate in the treatment of genetic mitochondrial diseases. Adv Drug Deliv Rev 60: 1478-1487.

Stacpoole PW, Nagaraja NV, Hutson AD (2003) Efficacy of dichloroacetate as a lactate-lowering drug. J Clin Pharmacol 43: 683-691.

Sun RC, Board PG, Blackburn AC (2011) Targeting metabolism with arsenic trioxide and dichloroacetate in breast cancer cells. Mol Cancer 10: 142.

Taketa K, Shimamura J, Ueda M, Shimada Y, Kosaka K (1988) Profiles of carbohydrate-metabolizing enzymes in human hepatocellular carcinomas and preneoplastic livers. Cancer Res 48: 467-474.

ter Voert EG, Heijmen L, van Laarhoven HW, Heerschap A (2011) In vivo magnetic resonance spectroscopy of liver tumors and metastases. World J Gastroenterol 17: 5133-5149.

Torizuka T, Tamaki N, Inokuma T, Magata Y, Sasayama S, Yonekura Y, Tanaka A, Yamaoka Y, Yamamoto K, Konishi J (1995) In vivo assessment of glucose metabolism in hepatocellular carcinoma with FDG-PET. J Nucl Med 36: 1811-1817.

Vander Heiden MG, Cantley LC, Thompson CB (2009) Understanding the Warburg effect: the metabolic requirements of cell proliferation. Science 234: 1029-1033.

Voqlein J, Tuttenberg J, Weimer M, Geriqk L, Kauczor HU, Essig M, Weber MA (2011) Treatment monitoring in glioma: comparison of dynamic susceptibility-weighted contrast-enhanced and spectroscopic MRI techniques for identifying treatment failure. Invest Radiol 46: 390-400.

Ward PS, Thompson CB (2012) Metabolic reprogramming: a cancer hallmark even Warburg did not anticipate. Cancer Cell 21: 297-308.

Welker MW, Lubomierski N, Gog C, Herrmann E, Engels K, Vogl TJ, Bechstein WO, Zeuzem S, Trojan J (2010) Efficacy and safety of sorafenib in advanced hepatocellular carcinoma under daily practice conditions. $J$ Chemother 22: 205-211.

Zhao F, Mancuso A, Bui TV, Tong X, Gruber JJ, Swider CR, Sanchez PV, Lum JJ, Sayed N, Melo JV, Perl AE, Carroll M, Tuttle SW, Thompson CB (2010) Imatinib resistance associated with BCL-ABL upregulation is dependent on HIF-1 $\alpha$-induced metabolic reprogramming. Oncogene 29: 2962-2972.

Zhao Y, Liu H, Liu Z, Ding Y, Ledoux SP, Wilson GL, Voellmy R, Lin Y, Lin W, Nahta R, Liu B, Fodstad O, Chen J, Wu Y, Price JE, Tan M (2011) Overcoming trastuzumab resistance in breast cancer by targeting dysregulated glucose metabolism. Cancer Res 71: 4585-4597.

Zhou Y, Tozzi F, Chen J, Fan F, Xia L, Wang J, Gao G, Zhang A, Xia X, Brasher H, Widger W, Ellis LM, Weihua Z (2011) Intracellular ATP levels are a positive determinant of chemoresistance in colon cancer cells. Cancer Res 72: 1-11.

This work is published under the standard license to publish agreement. After 12 months the work will become freely available and the license terms will switch to a Creative Commons AttributionNonCommercial-Share Alike 3.0 Unported License.

Supplementary Information accompanies this paper on British Journal of Cancer website (http://www.nature.com/bjc) 